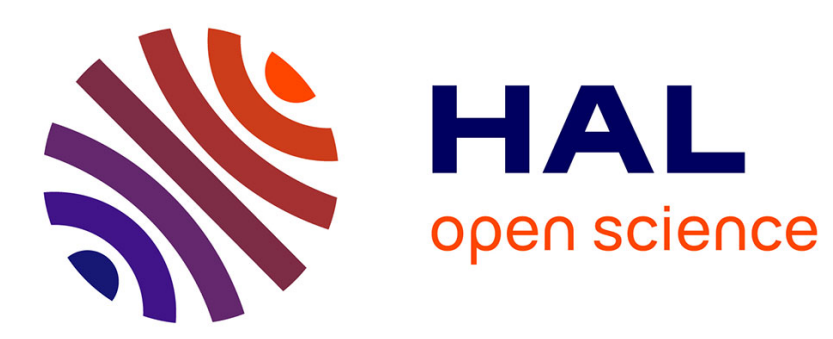

\title{
Stages and Pathways of Development of Nonprofit Organizations: An Integrative Model \\ Patrick Valéau
}

\section{To cite this version:}

Patrick Valéau. Stages and Pathways of Development of Nonprofit Organizations: An Integrative Model. Voluntas: International Journal of Voluntary and Nonprofit Organizations, 2014, 26 (5), pp.1894-1919. 10.1007/s11266-014-9501-y . hal-01243415

\section{HAL Id: hal-01243415 \\ https://hal.univ-reunion.fr/hal-01243415}

Submitted on 25 Sep 2019

HAL is a multi-disciplinary open access archive for the deposit and dissemination of scientific research documents, whether they are published or not. The documents may come from teaching and research institutions in France or abroad, or from public or private research centers.
L'archive ouverte pluridisciplinaire HAL, est destinée au dépôt et à la diffusion de documents scientifiques de niveau recherche, publiés ou non, émanant des établissements d'enseignement et de recherche français ou étrangers, des laboratoires publics ou privés. 


\title{
Stages and Pathways of Development of Nonprofit Organizations: An Integrative Model
}

\author{
Patrick J. Valeau
}

\begin{abstract}
Most research suggests that nonprofit organizations (NPOs) should professionalize in order to become more efficient. Yet, a growing body of literature emphasizes the importance of preserving some of their original grassroots culture. Based on a qualitative meta-analysis of 19 in-depth cases from the past decade, our integrative model contributes to this debate in three important ways: first, we suggest that most NPO pathways of development are characterized by the acquisition of a dual nature i.e., a community setting a value-based mission (stage 1) and a professional structure involving formal and centralized coordination aimed at effectiveness (stage 2); second, that this dual system often leads NPOs to an existential crisis characterized by contradiction and indetermination (stage 3); and third, that this indetermination constitutes a window of opportunity for deciders to more deliberately arbitrate the orientation adopted by their NPOs (stage 4). We discuss the role of deciders, beyond institutional pressures, to explain why the nonprofit sector is still relatively diverse. We propose voluntarism and institutional entrepreneurship as important mainstays of nonprofitness.
\end{abstract}

Résumé La plupart des recherches suggèrent que les organisations à but non lucratif (OBNL) doivent se professionnaliser pour devenir plus efficaces. Pourtant, un nombre croissant d'études insiste sur l'importance de préserver une partie de leur culture populaire d'origine. Basé sur une méta analyse qualitative de 19 études de cas approfondies des dernières dix années, notre modèle d'intégration contribue à ce débat de trois façons importantes: premièrement, nous affirmons que la plupart des voies des OBNL en matière de développement sont caractérisées par l'acquisition d'une double nature, c'est-à-dire une communauté définissant une mission reposant

Thanks to Jill Bennoson for her helpful comments and suggestions.

P. J. Valeau $(\bowtie)$

University of la Réunion, 26 avenue de la Victoire, 97417 Saint-Denis, Reunion, France

e-mail: patrick@valeau.com 
sur des valeurs (étape 1) et une structure professionnelle impliquant une coordination formelle et centralisée visant à l'efficacité (phase 2); deuxièmement, que ce double système conduit souvent les OBNL à une crise existentielle caractérisée par des contradictions et une indétermination (étape 3); troisièmement, que cette indétermination constitue une fenêtre d'opportunité pour les décideurs afin d'arbitrer plus délibérément l'orientation adoptée par les OBNL (étape 4). Nous examinons le rôle des décideurs au-delà des pressions institutionnelles dans le but d'expliquer pourquoi le secteur à but non lucratif est encore relativement diversifié. Nous proposons que le volontarisme et l'esprit d'entreprise des institutions soient d'importants piliers du secteur non lucratif.

Zusammenfassung Die meisten Forschungsstudien legen nahe, dass sich Nonprofit-Organisationen zur Erhöhung ihrer Effizienz professionalisieren sollten. Doch wird in der zunehmenden Literatur auch betont, wie wichtig es ist, dass sie einen Teil ihrer grundlegenden Kultur wahren. Beruhend auf einer qualitativen Metaanalyse von 19 gründlich erforschten Fällen in den vergangenen zehn Jahren trägt unser integratives Modell in dreifacher Hinsicht zu dieser Diskussion bei: Zunächst behaupten wir, dass sich die meisten Entwicklungspfade von Nonprofit-Organisationen durch die Aneignung einer dualen Natur auszeichnen, d. h. eine Gemeinschaft, die eine wertorientierte Mission festlegt (Stufe 1) und eine professionelle Struktur, die eine effizienzorientierte formale und zentralisierte Koordination beinhaltet (Stufe 2). Sodann behaupten wir, dass dieses duale System häufig zur einer Existenzkrise für Nonprofit-Organisationen führt, die durch Widersprüche und Untentschlossenheit gekennzeichnet ist (Stufe 3). Und schließlich behaupten wir, dass diese Unentschlossenheit den Entscheidungsträgern eine günstige Gelegenheit bietet, die Orientierung ihrer Nonprofit-Organisationen bewusster zu vermitteln (Stufe 4). Wir diskutieren die Rolle der Entscheidungsträger über die institutionellen Zwänge hinaus, um zu erklären, warum der Nonprofit-Sektor noch immer relativ mannigfaltig ist. Wir glauben, dass Voluntarismus und institutionelles Unternehmertum wichtige Stützpunkte der Gemeinnützigkeit sind.

Resumen La mayor parte de las investigaciones sugiere que las organizaciones sin ánimo de lucro (OSL/NPO) deben profesionalizarse para llegar a ser más eficientes. Sin embargo, un creciente número de material publicado hace hincapié en la importancia de preservar algunas de sus raíces culturales originales. Basándose en un metaanálisis cualitativo de 19 casos en profundidad de la última década, nuestro modelo integrativo contribuye a este debate de tres formas importantes: en primer lugar, sugerimos que la mayoría de las vías de desarrollo de las OSL/NPO se caracterizan por la adquisición de una naturaleza dual, es decir, una comunidad que establece una misión basada en valores (etapa 1) y una estructura profesional que implica una coordinación formal y centralizada dirigida a la efectividad (etapa 2); en segundo lugar, que dicho sistema dual a menudo lleva a las OSL/NPO a una crisis existencial caracterizada por contradicciones e indeterminación (etapa 3); en tercer lugar, que dicha indeterminación constituye una ventana de oportunidad para que las personas que toman las decisiones arbitren de manera más deliberada la orientación adoptada por sus OSL/NPO (etapa 4). Tratamos el papel de las personas 
que toman decisiones, más allá de las presiones institucionales, para explicar por qué el sector de las organizaciones sin ánimo de lucro sigue siendo relativamente diverso. Proponemos el voluntariado y el emprendimiento institucional como pilares importantes de "nonprofitness".

Behind almost every NPO, there is a grassroots community that created it and provided its initial values and core mission (Mintzberg 1983). However, over time, as NPOs develop professionally, i.e., change in order to improve the quantity and/or the quality of their actions, technical conformity and economic considerations often take over (Hwang and Powell 2009). The inherent tension between the value-based rationality of grassroots community and the need to be more efficiently organized has been observed by several scholars (e.g., Kelley et al. 2005; Kreutzer and Jäger 2011; Reid and Karambayya 2009). As pointed out by Rothschild and Stephenson (2009: 801), many NPOs first "reject outright the image of hierarchy and bureaucracy that (is) so central to the modernist project." These tensions often concern means and resources at first, but can rapidly generalize to values and goals, in other words to the mission. They constitute one of the specific challenges to the understanding of the development of NPOs.

On the one hand, NPO life cycle development literature is still divided as to the "best way" to deal with these contradictions. Mainstream models recommend overcoming these "resistances to change" in order to carry on with professionalization and efficiently achieve the core mission (e.g., Anheier 2005; Simon 2009; Stevens 2001). Yet, more and more authors object that this professional pathway degrades the "natural" performance of these grassroots NPOs (e.g., Sobeck et al. 2007; Graddy and Wang 2009). A third set of contributions promotes a middle orientation emerging from divided coalitions (Brandsen, 2009; Reid and Karambayya, 2009) or based on innovation (e.g., McDonald 2007; Jäger and Beyes 2010). On the other hand, literature looking at the effectiveness of NPOs has begun to acknowledge their diversity (e.g., Ebrahim and Rangan 2010; Moore 2000; Withman 2008). According to these contingent approaches, this diversity reflects different strategies based on different goals and values as much as different stages of development. The purpose of this paper was to embrace the development and diversity of NPOs within a unique framework. To what extent do NPOs follow the same stages of development? How and why do they end up adopting different orientations? Why do some NPOs preserve their community essence, while others turn essentially professional? Among the different forces at work in the development of NPOs, we will give specific attention to the role of deciders i.e., stakeholders in a position to influence their NPOs. Beyond determinism and emergence, to what extent do pathways of development reflect their "managerial discretion" (Finkelstein, 1987; Finkelstein \& Boyd, 1998) and "voluntarism" (Hrebeniak and Joyce, 1985)

NPO literature has provided many in-depth case studies reporting the development of one or more NPOs from the moment of foundation throughout the years. 
They all bring very rich illustrations as well as relevant insights. Yet, based on heterogeneous samples, having different theoretical foci (Hoon 2013), their conclusions remain "disparate." The meta-synthesis method "aims at building theory out of primary qualitative case studies that have not been planned as part of a unified multisite effect" (Hoon 2013: 522). Conducting such a meta-synthesis on 19 cases published over the past decade, this study aims to provide an integrative model of NPO development. This paper is structured in five parts: the first section gives an overview of the different orientations recommended by nonprofit literature. The second section introduces the qualitative meta-synthesis method. The third section presents a stage-by-stage comparative analysis of our 19 cases. The fourth section examines their pathways, connecting the differents stages, focusing on six of the cases. The fifth section relates this model to some of the main organizational theories imported into NPO literature. We conclude with a few thoughts on nonprofitness.

\section{Different Development Orientations Recommended by the Nonprofit Literature}

Almost all theoretical papers taking a life cycle or a professionalization approach to NPOs, as well most case studies reported in Table 1 ("A four stages integrative model" section), start with a first step driven by an inspired community. This stage is characterized by an informal structure relatively free from outside constraints. Later, different factors start to pressure NPOs to become more professional: time and growth (e.g., Martinez 2009; Simon 2009), changes in the environment (e.g., Medley and Akan 2008), but also normative demands from external stakeholders (e.g., Verbruggen et al. 2011; Hwang and Powell 2009; Pache and Santos 2010). Professionalization usually refers to an "organizational rationalization as expressed in the use of strategic planning, independent financial audits, quantitative program evaluation" (Hwang and Powell, 2009). It is based on more formal, centralized, and directive forms of coordination (e.g., Schmid 2006; Simon 2009). Professionalization aims to monitor and improve effectiveness i.e., input-output ratios confronting the resources used with the results obtained. (Sowa et al. 2004; Kanter and Summers 1987)

Yet, past literature has not succeeded in establishing the relationship between this professional model and effectiveness measured empirically. For instance, accountability does not always improve stakeholders' perception of the achievement of the mission (e.g., Ebrahim \& Rangan 2010) or increase donations (e.g., Sloan 2009). Board's strategic involvement does not systematically impact financer's ratings (e.g., Siciliano 2008). Entrepreneurial orientations do not automatically increase revenues and volunteering (e.g., Morrison and Salipante 2007). Strategic HRM practices such as work design do not always have a lot of impact on the effectiveness of volunteers and paid workers (De Prins and Hendericks 2007; Ridder and McCandless 2010; Rothschild and Stephenson 2009).

Moreover, a large number of the above papers point out some negative collateral effects of professionalization. They identify a main tension between the formal 
practices required by the professional model and the values initially set by the grassroots community. Many authors perceive a risk of contradiction between a "business like" approach and keeping up with the original mission (e.g., Carman 2010; McDonald 2007; Ebrahim \& Rangan 2010). Chew and Osborne (2005): 45 talk about a "tension between remaining committed to the core organizational mission and appropriately responding to a changing external environment." The cases presented in "A four stages integrative model" section illustrate this difficulty of working to expand and improve services while maintaining their grassroots. These contradictions appear to be deep and hard to reconcile.

Identifying the "resistance" of the grassroots community as one of the causes of the relatively poor correlations measured between professional organization and effectiveness, different models of development suggest fundamentally different solutions in terms of orientations that should finally be adopted:

- Orientation 1, the "pragmatic professional orientation," proposes going one step further toward the professional organization (e.g., Becker et al. 2011; Stevens 2001; Anheier 2005; Tucker and Summerfeld 2006; Simon 2009). In this model, grassroots community is a first stage. Its resistance to change has to be overcome to allow the next stage to unfold. Organizational professionals will take the lead (Hwang and Powell 2009). Professionalization is seen as a necessary condition for NPOs to carry on with their development (Mintzberg 1983).

- Orientation 2, the "grassroots community revival orientation," proposes to, somehow, preserve or even go back to this original stage (e.g., Batliwala 2002; Graddy and Wang 2009; Sobeck et al. 2007). Articles regularly debate the essence of NPOs: philanthropy (e.g., Sulek 2010), democracy (Rothschild and Stephenson 2009), and civil society (Muukkonen 2009). Drawing on the above concepts, these authors tend to emphasize a specific added value of grassroots NPOs that risks being lost with professionalization.

- Orientation 3, the "middle orientation," starts with a community informal stage, then transforms into an antithetic professionally organized stage, and finally finds a middle orientation stage. Ridder and McCandless (2010) include a third stage based on the strategic reevaluation of values. This middle orientation would be the right compromise between professionalization and grassroots (Brandsen 2009; Ospina et al. 2002).

These previous approaches to development all recognize the same beginning leading to the same tension between grassroots community and further professionalization, but finally propose different "best" orientations to move on. These best orientations are based on different norms of effectiveness (Jun and Shiau 2012), associated with different definitions of nonprofitness, but they have in common the same teleological assumption that there would be an endpoint to development. Stepping away from this assumption, our research question focuses on the contingencies of the forces associated with these three different orientations over time. To what extents can deciders navigate between them in order to achieve their own vision of the mission? To what extent can they express their voluntarism and actually choose between the three above orientations? To what extent can they 
develop enough managerial discretion to inflect the orientation adopted by their NPOs?

\section{The Qualitative Meta-Analysis Method}

Qualitative meta-analysis consists in analyzing "second hand" cases from previous research in order to extend existing theory (Hoon 2013). Therefore, the main challenge lies in comparing heterogeneous data not designed to be treated together. However, meta-analytical theory building is not completely different from the traditional grounded theory building based on first-hand cases: the model is provisionally achieved when reaching a saturation point i.e., when accounting for all the available data. Summarizing and revisiting Hoon's (2013) approach to qualitative meta-analysis, we consider three main steps.

Step 1 consists in defining the conceptual framework and targeting relevant case studies from previous literature (Hoon 2013). Beyond explicit key words such as such as "development" and "life cycles," our selection of the literature studied integrates a series of texts and models referring to the concepts of "professionalization" and "grassroots" combined with "stages" and "changes." We targeted papers published between 2002 and 2012 in three major journals entirely devoted to the nonprofit sector: Voluntas, Nonprofit \& Volunteer Sector Quarterly (NVSQ), and Nonprofit Management Leadership (NML). We then parsimoniously completed this database with other sources when we felt they were bringing forgotten or untackled dimensions. For instance, Reid and Karambayya (2009), in Human Relations, originally described different forms of dual leadership. Gawell (2013), in Voluntas, was a more recent reference, but provided a renewed conception of social entrepreneurship. In addition to their relevance to our problems, case studies were selected depending on the amount of exploitable data they provided.

Step 2 deals with the extraction and coding of the data (Hoon 2013). Appendix Table 1, presented in the next section, displays the data extracted from each of 19 cases selected, dispatching it between four main categories corresponding to the four stages forming the basis of our model. These data were then summarized and coded in relation to different sub-categories. For instance, we tracked the deciders involved at each stage. As in classical qualitative research, the coding emerged from an iterative process: we progressively adjusted our categories and sub-categories to the variations introduced by the cases being analyzed. Table 1 can be read either vertically, for a comparative analysis of different NPOs at a given stage, or horizontally, showing the evolution and change of a given NPO through the different stages.

Step 3, building and discussing theory, is, according to Hoon (2013), the ultimate purpose of qualitative meta-analysis. Figure 1, presented in the fourth section, focuses on five cases in order to explore "a causal description of the forces at work" (Miles and Huberman 1994: 4), our main assumption being that different stages are characterized by different forces. As important as the model itself, the theoretical discussion ("Discussion" section) is connecting the forces thus identified to theories previously used in NPO literature. 


\section{A Four Stages Integrative Model}

This section presents the results of our meta-analysis based on the 19 second-hand cases reported in Appendix Table 1. Our model reinterprets the beginning of NPOs in terms community building (stage 1) and professional organizing (stage 2), then redefines the tensions in between building community and the professionalization process in terms of "existential crisis" (stage 3) and finally considers five possible orientations to decide between (stage 4). This section compares the situations of the different NPOs, stage by stage, using all the cases from Table 1, at least once, in order to illustrate the degree of diversity of NPOs. However, we will refer more systematically to six of them: Detroit Youth NPOs (case 1), French NonGovernmental Organizations (NGOs) (case 2), San-Francisco Syringe Exchange (case 3), Centraide (case 4), Cancer Council Queensland (case 5), and the Brazilian Hospitals (case 6). These are the ones whose completed pathways will be examined in the next section.

\section{Stage 1: The Community Stage}

Community stands, in our model, as a stage as important as professionalization, corresponding to the acquisition of a fundamental essence setting the values of NPOs. Mintzberg (1983) referred to them as "missionary organizations" coming with a "truth." For instance, the first stage of French NGOs (case 2), with the goal of helping developing countries, was inspired by anti-conformist, anti-capitalist leanings. Members of Centraide (case 4), a community foundation in Montreal, felt "closer to the needy than to the wealthy donors." Performing Arts NPOs (case 17) defined their specific sensibility and editorial line during this first stage. This stage's challenge consists in building shared ways to act, talk, and think among members i.e., a culture. The latter cannot be taken for granted, but is the result of a long process.

Appendix Table 1 shows that a large majority of the 19 NPOs examined started without formal structure. Apart from the Brazilian Hospitals (cases 6), which, because of their activity, rapidly adopted a professional form of organization, all the other NPOs began as a few individuals willing to provide the same service or to defend the same cause, but who did not always know each other very well. The members of a Patients Self-Help Group (case 11) first met because they were confronted with the same illness. The three founders of Cancer Council Queensland (case 5) shared a common passion but had never worked together. The Ufungamano initiative (case 13), which led to a new constitution in Kenya, started as a protest meeting event. The San-Francisco Syringe Exchange NPO (case 3) began as a group of individuals from different backgrounds, such as nurses and social workers, working illegally in the street with drug addicts. Like in the above cases (cases 3, 5, 11,13 ), actors taking part in this community stage are often volunteers. They can sometimes be paid workers, like the artistic team of the Performing Arts NPOs (case 17). The Detroit Youth NPOs (case 1) included both volunteers and paid workers. Some NPOs can also unite multiple groups. This was the case for Homenet (case 7) which integrated different groups of self-employed women and for Centraide (case 
4) which regrouped foundations from different communities of Montreal. In all these cases, working together was a specific challenge.

Cases often report passionate and emotional beginnings involving a lot of long discussions and intense first time actions. For instance, in the San-Francisco Syringe Exchange (case 3), "high risk activism" durably bonds members together. The Kenya Ufungamano Initiative (case 13) grew stronger, meeting after meeting, success after success, as it attracted a larger audience. French NGOs (case 2) were launched by young western volunteers sharing their first work experience. Nevertheless, some of the cases examined provide enough details to distinguish between two sub-phases: the "founders sub-phase" corresponds to the very first gathering of individuals establishing the culture, while the "socialization subphase" starts when the latter is transmitted to new members. Thus, even long after its creation, new members of the Homeless NPO (case 8) were systematically told the story behind its foundation. More specifically, the Cousin Fundation (case 18), the Kenya Youth Sport NPO (Case 19), and some of the Spanich NGOs (case 12) had been initiated by a single "charismatic leader" who had the vision of the mission even before sharing it with any other members. Attac (case 9), one of the world's biggest advocacy NPOs, started after an editorial written by the chief editor of the new paper "Le Monde Diplomatic." However, in all the cases, becoming a community involved a long period of incubation.

Proposition 1 NPOs need time to fully and durably acquire a community nature.

Stage 2: The Professionalization Stage

The need for professionalization depends on the type of activity carried out (e.g., case 6-the Brazilian Nonprofit Hospitals), but can also arise when NPOs intend to increase the volume and/or the quality of the services and goods they provide. Cases gathered in Appendix Table 1 show that NPOs often engage in this orientation after experiencing practical problems with informal community organization. For instance, members of San-Francisco Syringe Exchange (case 3) simply wanted to stop running out of needles. The Performing Arts NPOs (case 17) needed more money to acquire desired artists. The Patient Self-Help Groups (case 11) were trying to sell their services to non-members in order to carry on growing. The Job Assistance Services (case 14) needed to stop the decline of its client base. Even with limited development ambitions, the Detroit Youth NPOs (case 1) felt the need to become a little more organized. For all these technical and economic problems, increased professionalization seemed to be the solution.

Depending on the NPO, the process of professionalization can be launched by different deciders. This can be done by the founders, like in the Cancer Council Queensland (case 5), where the three initiators always continued to develop new ambitions. In the San-Francisco Syringe Exchange (case 3), the decision to become legal, and therefore to professionalize, was made by a small group of senior volunteers. The ambitions of internal actors can also be supported by external consultants and trainers. This was the case, for the Detroit Youth NPOs (case 1) and for the Job Assessment Centre (case 14). In many cases, internal stakeholders 
decided to hire new managers with the requisite skills to become more professional, like in French NGOs (case 2) which began "replacing the old guard, notably the unreconstructed cold warriors (...), with a new breed of managers and careerminded recruits" (Cumming, 2008: 390).

Case studies referred to in Table 1 try to catch the momentum of the professional process. They often report a time lag following a first decision. This was the case in the San-Francisco Syringe Exchange (case 3) where, having made the decision to become legal, the transformation spanned a number of years. Similarly, for NPOs that chose to hire a manager, their takeover always took a while. In the Performing Arts NPOs (case 17), the new executive directors often slowly became as important as the artistic directors. In Cancer Council Queensland (case 5), despite a rapid first step toward professionalization, the implementation of a more sophisticated performance management system had, finally, to go through a long consultation process. Thus, the professionalization phase is not only technical or economical but also social, with deciders trying to rally the rest of the community to their vision of the development of their NPO and convince them of the legitimacy of the associated means.

Proposition 2 Once the decision to professionalize is made, its implementation takes time.

Stage 3: The Existential Crisis Stage

Lots of the NPOs presented in Appendix Table 1 retain values and goals from stages 1 and 2, not only acknowledging the usefulness of professional organization, but also considering the essentiality of community. Existential crisis starts when these different values and goals recurrently contradict each other, leading to dilemmas. Table 1 presents "in vivo" coding summarizing the subjects of hesitation and problems a priori causing the crisis. Minor problems first tend to occur at the means level. This was the case for the San-Francisco Syringe Exchange (case 3) where formal coordination was at odds with previous practice, but obviously contributed to a better service. Similarly, in the Performing Art NPOs (case 17), the new management allowed them to raise the money needed to recruit the targeted artists. Conversely, years after its creation, the Brazilian Nonprofit Hospitals (case 6) welcomed their first volunteers, but did not know what tasks to give them. Major problems arise when contradictory goals and values lead to conflicting solutions. The literature provides many examples of such dilemmas. For instance, French NGOs (case 2) were faced with the government's demand for more transparency, while their militant public donors still had faith in their independence. Performing Arts NPOs (case 17) progressively experienced deeper recurrent opposition between artistic boldness and a more commercial approach to art performance. Centraide's (case 4) new managers needed to act quickly, while the democratic governance at the roots of its creation required more time. Detroit Youth NPOs (case 1) found it difficult to improve their effectiveness while keeping their "homegrown" qualities. However, the main and most frequent dilemmas reported in NPO literature obviously concern human resources management, with a lot of research recounting 
the gap between equal and participative "informal chaos" and the division of work. This was the case, in particular, for French NGOs (case 2), for San-Francisco Synringe exchange (case 3) or for Patients Self-Help Groups (case 11). Practical problems related to means often gradually reveal deeper divisions concerning values and goals.

Problems associated with existential crisis are brought up by the actors committed to goals and values from stages 1 and 2 . The most frequent configuration reported among the 19 cases examined is the one of the two coalitions defending different visions, yet a less frequent situation, or less focused aspect, is when existential crisis takes place within a single group or even with just one decider. Existential crisis often takes the form of a social and political "identity crisis" i.e., a disagreement or even a conflict between two inner coalitions, often from different generations, divided about the essence of their NPO? This was, noticeably, the case for French NGOs (case 2), for San-Francisco Synringe Exchange (case 3), or for the Patients Self-Help Groups (case 11). Reid \& Karambayya (case 17-2009) have listed a series of scenarios in which the disagreements between management and artistic directors about their Performing Arts NPOs (case 17) may or may not turn into a conflict disseminating to other members. In some cases, one coalition will simply quit, as when Cancer Council Queensland (case 5) experienced a $15 \%$ turnover in 6 months after professionalizing.

However, existential crisis can also take the form of a more psychological inner emotional and cognitive conflict, occurring when a given group of deciders realizes that they cannot have it all, but are not sure about which orientation should be given priority. Muslim (case 16) and Christian humanitarian NGOs (case 12) faced similar hesitations concerning the place they should give to faith when attempting to join the mainstream movement of international humanitarian aid. The Detroit Youth NPOs (case 1) were tempted to adopt more professional routines, but did not want to give up some of their former practices, like recruiting in the local neighborhood. The chairman and the CEO of VLN (case 15) were equally torn apart between developing explicit deliberated strategy planning answering external stakeholder's requirements and keeping up with the strategy naturally emerging from internal stakeholders. The Cousins Family's heir (case 18) was frustrated with the limited impact of traditional funding and was looking for another orientation to operate. Hafsi \& Thomas (2008) use the word "disoriented" to qualify the state of the members of Centraide (case 4) when split apart between inner democracy and effectiveness.

This crisis may come progressively from repeated difficulties over minor issues like in Centraide or, more suddenly, from a dilemma dealing with a major issue like for San-Francisco Synringe Exchange (case 3) when considering regularizing their practices. During existential crisis, all issues collide with each other. Thus, existential crisis leads to state of confusion between cognitive dissonance and the void left by the loss of certitude about what to do to carry on with the mission. This phase occurs when individuals start to address questions related to "who are we?" and "where we are going?". Cumulating values and goals inherited from stages 1 and 2 give birth to a new system characterized by indetermination i.e., a "state of being uncertain or undecided" (Oxford dictionary, 2013). The contribution of our 
model really starts here, introducing this moment of hesitation and uncertainty not as a transition but as a stage.

Proposition 3 Existential crisis comes from recurring or sudden contradictions between goals and values acquired during the previous community and professional stages.

\section{Stage 4. The Arbitration Stage}

The most observable aspect of this stage, first reported in Appendix Table 1, is the orientation finally taken by the NPO in the medium term. ${ }^{1}$ The different possible orientations are displayed in Fig. 1. The "very high" professional orientation, for instance, adopted by Cancer Council Queensland (case 5) and the "very high" grassroots orientation adopted by Attac-Sweden (case 9) are opposite to one another, but both represent radical choices, preventing any further dilemmas by following just one logic of action. Orientation 3: the middle orientation, adopted by some of the Performing Arts NPOs (case 17) or by VLN (case 15), could be seen as an ideal combination of community and professionalization, but in practice this orientation is not without difficulty. Sooner or later, there may be an "all or nothing" issue leading to a less neutral orientation, such as becoming or not becoming legal (case 3-San-Francisco syringe exchange), serving or not serving non-members (case 11-Patients self-help group), splitting the organization or staying together (case 7-Self-employed women's advocacy group). In these cases, an arbitration had to be made between two opposite or two contrasted options, leading to allowing one vision to completely (orientations 1 and 5-Fig. 1) or partially (orientations 2 and 4-Fig. 1) take over from the other.

Who takes part in the decisions defining the orientation finally followed by an NPO is of great importance for the understanding of its development. When a crisis occurs between two opposite coalitions, a status quo is always possible, as illustrated in some of the Performing Arts NPOs (case 17), where the artistic director and the executive director were sometimes able to agree on a middle orientation. Yet, in many cases, different points of view turn into disagreement and, possibly, conflict. Therefore, the orientation finally retained emerges as a result of the confrontation between forces at work, one of the coalitions, completely or partially, taking the lead over the other one. Often, professional coalition takes over from the grassroots like in San-Francisco Syringe Exchange(case 3), which will usually mean that paid workers run the NPO, like in the Patient Self-Help Groups (case 11). Yet, sometimes, as with Detroit Youth NPO (case 1) or with the French NGOs (case 2), the grassroots coalition still dominates but with a minimum acceptance of professional standards. In this case, the orientation tends to emerge from the interaction between the different coalitions of stakeholders involved.

A second and fundamentally different scenario is when one coalition or one individual stands alone from the beginning like in Cancer Council Queensland (case 5) or after having taken over other coalitions like in the Patient Self-Help Groups

\footnotetext{
${ }^{1} \mathrm{Cf}$. conclusion about the possibility of further development in the long term.
} 
(case 11). In both cases, they will arbitrate on their own. The orientation chosen is then the result of a more complete form of bounded rationality. Orientations 2, 3, and 4 (Fig. 1- "An integrative model of pathways" section) become a rational optimization of one approach under the constraint of a minimum of respect for the other. Orientation 3 was retained by VLN's chairman and CEO (case 15) through a "balancing act" "placing them on a razor's edge," "blending" professional deliberate and community emergent modes of planning (Morisson and Salipante 2007: 209). Orientation 4 was adopted by the Cooperative Bank (case 10) when trying to "foster economic growth without damaging the social mission" (Jäger and Beyes 2010: 82). Orientation 2 emphasizes the development of community under the constraint of a minimum of professionalization, as for the Detroit Youth NPOs (case 1): the objective of the project was to moderately enhance their management capacity, while retaining, as far as possible, their grassroots qualities. All these orientations were chosen by one coalition trying to take into account multiple commitments to multiple goals and values. In this case, the voluntarist arbitrations of deciders can inflect their NPO's orientation. Such rationality may be adopted by any coalition, yet it becomes less visible and less effective when the situation becomes conflictual.

Stage 4 is a turning point when NPOs engage themselves more definitely toward a given orientation, yet for this stage, like for the previous ones, time remains an issue. Once the arbitration has been made, things slowly settle down. This is expressed by San-Francisco Syringe Exchange (case 3), "Many of the obstacles were thereby removed. In response, the group gradually reorganized, shifting its structures and procedures" (Kelley et al. 2005: 382). Arbitration is progressively retained through the repetition of decisions and actions aiming to solve similar dilemmas by adopting the same orientation. Stage 4 can also occur sooner when there is a deadline. For instance, in the Performing Arts NPOs (case 17), artistic and financial contradictions have to be resolved at the same period every year, because of the obligation to provide a program and a balanced budget. Dilemma after dilemma, arbitration after arbitration, a general orientation takes form, becoming a routine and a norm.

Proposition 4 An NPO's orientation is gradually adopted through the repetition of similar arbitrations.

\section{An Integrative Model of Pathways}

The previous section highlighted the differences between NPOs at the different stages. This section constitutes a first attempt to explain pathways i.e., the development of a given NPO across the four different stages of our model. The five orientations $^{2}$ represented in Fig. 1 are, to a certain extent, available to all NPOs, yet we contend that their probability of occurring will depend on their characteristics at

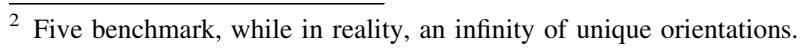




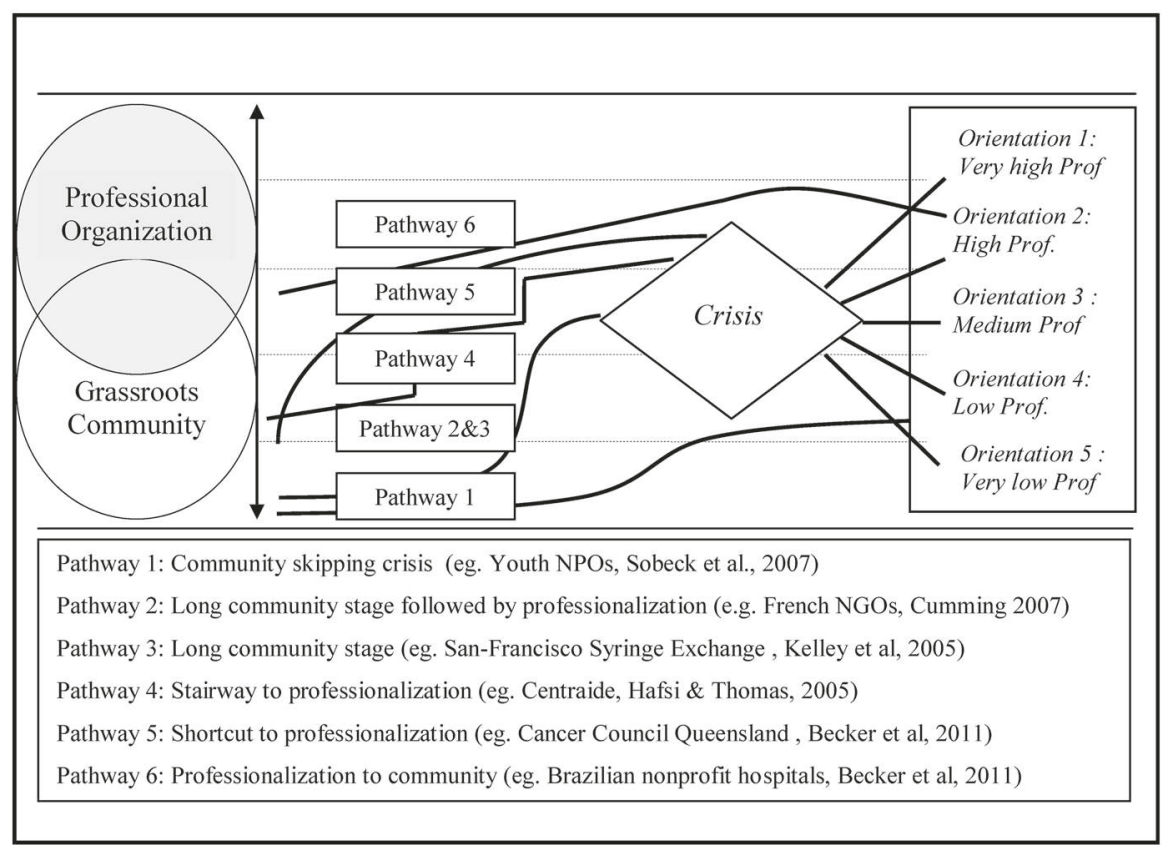

Note. The level of professionalization of the orientation adopted (on right side) corresponds to the relative importance given to professionalization compared to grassroots.

Fig. 1 Stages and pathways of development of nonprofit organizations

the different stages they have been through. In order to explore this issue, we will concentrate our analysis on our 6 focus cases chosen for their diversity.

Pathway 1

The pathway of the Detroit Youth NPOs is characterized by a long grassroots community phase, involving volunteers and paid workers, followed by a limited professionalization phase initiated by external stakeholders. New Detroit authorities provided them with funds and consultant support related to leadership, organization strategy planning to help them achieve their goals. Given the cautious help offered aiming to preserve the NPO's grassroots and the limited ambitions of volunteers and paid workers, the result was a smooth enhancement of their capacity, without major tensions.

Pathway 2

The pathway of French NGOs was also characterized by a long grassroots stage that contributed to a strong culture. The pressure to professionalize came from the government that was providing funds and from other NGOs who had done so. The process was already on its orientation, with the recruitment of a new breed of 
professionals, when the "old guard" struck back, finding external support with individual private donors valuing their militancy. Major crisis found an end with the adoption of an atypical grassroots orientation.

Pathway 3

San-Francisco Syringe Exchange started in the streets as a group composed of former drug addicts, nurses, and social workers illegally exchanging drug addicts' syringes to protect them from the HIV infection. In order to stop running down of syringes, the group of senior volunteers, founding members of the NPO, decided to professionalize and to give it a legal form. This change led to a major crisis, destabilizing volunteers' identity built on shared "high risk" experience. Despite the loss of commitment from some volunteers, this NPO finally achieved a high level of professionalization.

Pathway 4

Centraide is somehow the most complex case with a strong community stage marked by the fusion of five foundations from different cultures but sharing the same grassroots values. Given the size of the new entity, the successive new presidents and the managers they recruited engaged in a series of attempts to professionalize. These attempts progressively led to a major crisis and loss of direction. The new female president, an outsider, succeeded in rebuilding Centraide's identity through the assembly of all stakeholders, organizing meetings with financers as part of a participative governance.

Pathway 5

Cancer Council Queensland was created by three "passionate" volunteers who always kept the power of decision. The NPO started its professionalization process almost at its creation and kept innovating in that direction. An important step was to measure and improve the level of effectiveness achieved at the individual level through implementation of an employee performance management system. Employees did not voice their disagreement directly, yet $15 \%$ of them left in 6 months. A consultation was then organized to discuss the criteria used in evaluations, after which the implementation of the new system was successfully achieved.

Pathway 6

Because of their sector of activity, Brazilian nonprofit hospitals needed to start with a professional structure. The originality of their situation lies in the development of elements of a grassroots culture, coming afterward. The recruitment of volunteers first aimed to find kind citizens with good intentions willing to make minor contributions. Yet, progressively, volunteers started to contribute to fund raising and 
other strategic activities. There was no major crisis, but an unexpected emergent strategy.

Considering the six cases above, completing proposition 1, we consider that the length and depth of the community stage will logically determine its chance of surviving the professional development. The process leading to the creation of grassroots culture has to be completely achieved in order to create a sustainable imprint. Its survival will become salient when confronted with professional development. Existential crisis does attest to the dual nature, and the NPO has acquired and retained (pathways 2, 3, and 4). Pathways 2, 3, and 4 illustrate this situation. Pathways 5 and 6 skip the crisis, because NPO professionalization has happened too quickly and too fastly, community did not have time to emerge. Pathway 1 also skips the crisis stage because the professionalization stage did not go far enough to destabilize the grassroots communities. Pathways 1, 5, and 6 have in common their avoidance of dilemmas because of their single nature.

Proposition 5 The longer the community stage lasts, the deeper the crisis will be when professionalizing.

Dual nature and existential crisis could appear as a source of complication and confusion making NPO management and development seem very "loose." Yet, we argue that such crisis enhances the possibility for deciders to make voluntarist arbitrations based on their preferences. Pathways 2 and 3 start in exactly the same orientation, while pathway 4 appears relatively similar with a long grassroots phase followed by an intense professionalization stage. However, these three pathways end up with very different orientations: San-Francisco Syringe exchange chose a mainly professional orientation, Centraide found an integrative middle orientation, and French NGOs have kept a militancy orientation. Figure 1 illustrates this proposition with these three pathways entering the crisis diamond possibly leading to any one of the five orientations, while pathways 1,5 , and 6 only connect with a limited number of possible orientations, their probability of radically changing the latter being very low. Thus, we contend that crisis and arbitration are a source of diversity.

Proposition 6 The deeper the crisis is, the greater the opportunity will be for voluntarist arbitration.

\section{Discussion}

Our research question was why NPOs remain relatively diverse when their development seems to follow similar stages resulting from the same forces? Our main sub-question was focused on the role of deciders and the extent to which they are able to influence the development of their NPOs? "A four stages integrative model" section provided a detailed description of "what" these stages are and "how" they unfold, while "An integrative model of pathways" section started to explore "the whys underlying the reconstituted what and how" (Whetten 1989: 489), arguing that existential crisis constitutes a form of indetermination opening 
the door to more managerial discretion. In the present section, we discuss our propositions, connecting them to the nonprofit literature. Three theories appear to be frequently referred to the sociological approach (Durkheim 1893), the newinstitutionalist resource dependency approach (DiMaggio and Powell 1983; Pfeffer and Salancik 1978) and the stakeholders theory (Freeman 2010). Each of them emphasizes "different forces at work" (Miles and Huberman, 1994). We argue that the strength of the latter as well as the influence of deciders varies, depending on the stage of development the NPO is going through.

The influence of deciders is not the most frequent focus when analyzing NPO development. Yet, five of the papers examined in our meta-analysis provide useful and complementary theoretical backgrounds helping to define this factor. Referring to Barnard (1938), Reid and Karambayya evoke leader's ability to provide a "coordinating vision". Drawing on (Mintzberg and Waters 1985), Morisson and Salipante (2007) show how a leader pair "blends emerging and deliberate strategies" contributing to broader accountability. Referring to Hrebeniak and Joyce (1985), Hafsi and Thomas (2005) focus on the president's "strategic choice beyond determinism." Van Slyke and Newman (2006) and Gawell (2013) both take an "entrepreneurship" perspective, the first authors focus on the "personality of the founder", while the second introduces "perceived necessities" as an alternative to perceived opportunity. These five contributions foresee space for "voluntarism" (Hrebeniak and Joyce 1985) and "managerial discretion" (Finkelstein and Boyd 1998) i.e., a managerial latitude of action to express a specific vision. Referring to Simon (1984), we integrate deciders' specific visions, goals, and values as part of a bounded rationality decision, based not only on the available information but also on their "preferences." With this in mind, we question to what extent, through the different stages of its development, their NPO's orientation reflects these "preferences."

Our first proposition insisted on the time necessary to build a strong grassroots culture. Almost all cases reported in Table 1 emphasize the strength of the bonds between members during this early stage (e.g., Cumming 2008; Kelley et al. 2005; Kreutzer and Jäger 2011). Members of a given community NPO often share the same orientations of acting, talking, and thinking, in other words, they have the same culture. Thus, the grassroots stage is often addressed from a sociological perspective, focusing on NPOs as "social facts" (Durkheim, 1893) i.e., a collective identities overtaking and influencing individuals' rationality (e.g., Kreutzer and Jäger 2011; Rothschild and Stephenson 2009). These contributions highlight some specific forces at work in NPOs during this stage, acknowledging a strong social order rather than an absence of organization. Yet, they often skip the initial process leading to such a culture. For instance, Detroit Youth NPOs already had a strong culture when Sobeck et al's case starts describing their evolution when New Detroit Authorities start providing them with technical support. Part of entrepreneurship literature has focused on this pre-organization phase, for instance, Bird et al. (1992) explain that founders have to "act as if" the organization already existed, till the others start getting committed to it. Drawing on this approach, we argue that community and culture of NPOs are not totally natural and spontaneous, but are, to a certain extent, the result of entrepreneurial labor carried out by inspired founders. 
The founding role of certain deciders has to be taken into account when analyzing this stage.

Our second proposition related to the time necessary to deal with the sociopolitical aspects of professionalization. Greiner's (1998) model describes the different transitions from a creative informal phase to more directive forms of coordination through which organizations have to pass as they grow. According to Mintzberg (1983), these "physical" laws of organized action apply to NPOs. Yet, part of the NPO literature has adopted a more critical perspective inspired by new institutionalism (DiMaggio and Powell 1991), redefining professionalization as a socially constructed norm (e.g., Hafsi and Thomas 2005; Verbruggen et al. 2011; Hwang and Powell 2009). In this view, the role of deciders consists in actively "adapting" to the norms of external stakeholders who provide the resources they need (Pfeffer and Salancik 1978). They have to compete according to these rules in order to survive (Baum and Amburgey 2002). Early versions of social entrepreneurship (e.g., Dees 1998) have embraced this point of view, highlighting the ability of a new breed of competitive entrepreneurs to acquire scarce resources. Assuming that professionalization is either desirable or inevitable, these deciders interpret the crisis as grassroots resistance to change that has to be overcome (Coch and French 1948). This was the case in Cancer Council Queensland (case 5), where they slowed down the process to let employees get used to the assessment program, but otherwise carried on as planned.

Propositions 3 and 5 claimed that crisis comes from the full acquisition of a dual nature: a grassroots community and professional structure. The confrontation of two generations, inherited from these two social orders, is at the heart of a lot of case studies included in our qualitative meta-analysis. Taking a more critical look at professionalization norms, these generations can be considered as equal internal stakeholders (e.g., Jun and Shiau 2012). Stakeholder's theory (Freeman 2010) postulates that anyone concerned by the organization's actions has the legitimacy to voice an opinion. Some of the case studies provide in-depth, detailed reports about discussions, negotiations, and fights among stakeholders (e.g., Kelley et al. 2005; Reid and Karambayya 2009; Kreutzer and Jäger 2011). The orientations resulting from these confrontations are emergent in nature (Mintzberg and Waters 1985) and i.e., they occur despite or without deliberation. Part of the nonprofit literature values these orientations because they come from the bottom (Morrison \& Salipante 2007), yet Mintzberg (1983) pointed to the risk of such NPOs, characterized by divided coalitions, becoming a political arena. Thus, in this view, the role of the deciders can be that of a regulator and mediator, organizing a participative governance, making sure that stakeholders fairly negotiate. Therefore, for these deciders, crisis and collective arbitrations are part of the same democratic process. One of the best examples is Centraide's president (case 4) trying to involve all stakeholders within a participative governance. Similarly, VLN's chairman and CEO (Morisson \& Salipante 2007) developed a broadened accountability, blending the official professional deliberate strategy with informal strategies emerging from the grassroots forces.

Propositions 4 and 6 argued that dilemmas leading to crisis can be solved by deciders' arbitrations. Dilemmas come from multiple commitments to multiple goals 
and values. Most cases provide examples of situations when deciders cannot satisfy all of these, when serving one deprives another (Pache and Santos 2010). From this perspective, the crisis takes a more cognitive turn. Such situations can be compared to that of mathematicians trying to simultaneously maximize several functions based on independent variables. Different functions can momentarily share the same maximum, but will probably sooner or later evolve in different orientations (Bui and Alam 2008). This is when the optimization system leads to a tie requiring "postanalysis subjective arbitration" (Bui and Alam 2008), in other words arbitration based on "preferences" (Simon 1984). From this perspective, the role of deciders can be more engaged, taking sides or, in line with Barnard (1938), developing their own coordinating vision of their NPO. In this perspective, crisis and arbitrations can constitute opportunities to communicate on this vision. This was the case for SanFrancisco Syringe Exchange (case 3), where after long hesitations, the group of senior volunteers controlling the board, finally decided to make their NPO legal.

The cases used in our meta-analysis show a large variety of situations in terms of who are the deciders and whether they remain the same or change along the different stages of NPO development. In some cases, the founders keep the lead through all the stages, while in other deciders keep changing. Thus, we should ask the question who has the right and the duty to voluntarily inflect the development of NPOs? On the one hand, in line with part of the entrepreneurship literature, Schmid (2006) considers that deciders should adapt their style and be replaced depending on the characteristics of the stage of development of the NPO. On the other hand, we have shown that deciders can, to a certain extent, initiate the different stages, in particular for the creation of the community stage or for the launch of the professionalization process. Drawing on stakeholder's theory, we also argue that almost anyone in the NPO can provoke a crisis, raising the issue of mission drift when they think present deciders are following the wrong direction. These autopromoted deciders can either be seen as resistance to change (Coch and French 1948) or as institutional entrepreneurs (Battilana et al. 2009) changing the norms defining the internal and, eventually, external contexts, creating the necessary conditions for a voluntarist orientation of their NPO. This was the case for French NGOs. The French government started to pressure them to professionalize and a new breed of managers was recruited for that purpose. But the "old guard" struck back, voicing their opinion about professionalization and getting help from private donors supporting their militancy. As a result, French NGOs (Case 2) were able to go back to a mainly grassroots approach to their development.

Proposition 4 indicated that an orientation is gradually established through the repetition of arbitrations. Crisis is necessary for major changes (Watzlavick et al. 1974), yet cannot be a permanent stage because it puts NPOs at risk of turning into a political arena threatening their survival (Mintzberg 1983; Reid and Karambayya 2009). Arbitration after arbitration, the orientation will progressively be adopted, till the next crisis. This cycle combining stages of crisis and stages of stability can be found in almost every theory of change: from equivocality to retention (Weick 1995), from confusion to a new framework of thought (Watzlavick et al. 1974), from defreeze to refreeze (Lewin 1952). Thus, we argue that the extent to which 
deciders are able to influence the development of their NPOs will be far greater in times of crisis, in other words, major change seldom occurs without tensions.

\section{Limitations and Future Research}

The main limitation of this theoretical model is that it relies on the re-interpretation of cases from former research. The qualitative meta-analysis method consists in working on available data, trying to include all these fragments within a unique framework (Hoon 2013). However, first-hand data will be necessary to confirm and complete this model. Statistical data could test some of our hypotheses: in particular, the effect of the length of the grassroots stage on the intensity of further crisis and the effect of the intensity of the crisis on the choice of orientation. Qualitative case studied of large NPOs experimenting successfully with "communitarian" organizations may also be of major interest. How did they overcome institutional pressure to professionalize? How have they been able to sustainably grow with less formal coordination? What was the part played by leaders in this development? A third research avenue would consist in refining the model, by integrating cultural and legal aspects of the environment: beyond professionalization, do national context introduce specific norms? To what extent do they favor or restrain diversity?

\section{Conclusion}

Our model contributes to nonprofit literature on development by giving further explanations of their diversity. A main source of diversity comes from decider's preferences, visions, and projects, but the extent to which they will be able to express them will vary along the stages of NPO development. We insist on the importance of the early stage of community to leave a cultural "imprint" strong enough to survive further professionalization. Beyond community as such, dual nature emphasizes latent or manifest equivocal indetermination that will sometimes lead to crisis, allowing major change and major influence from deciders and therefore major diversity to develop in the nonprofit sector.Thus, this model highlights the place of voluntarism and institutional entrepreneurship as important mainstays of nonprofitness. Beyond internal and external constraints and norms, the role of deciders, whoever they are, can consist in feeding their NPO mission with a voluntarist vision and engaging the changes required for its achievement. Whereas social entrepreneurs try to adapt their NPO to its environment, institutional entrepreneurs foresee the possibility of changing it.

\section{Appendix}

Table 1 


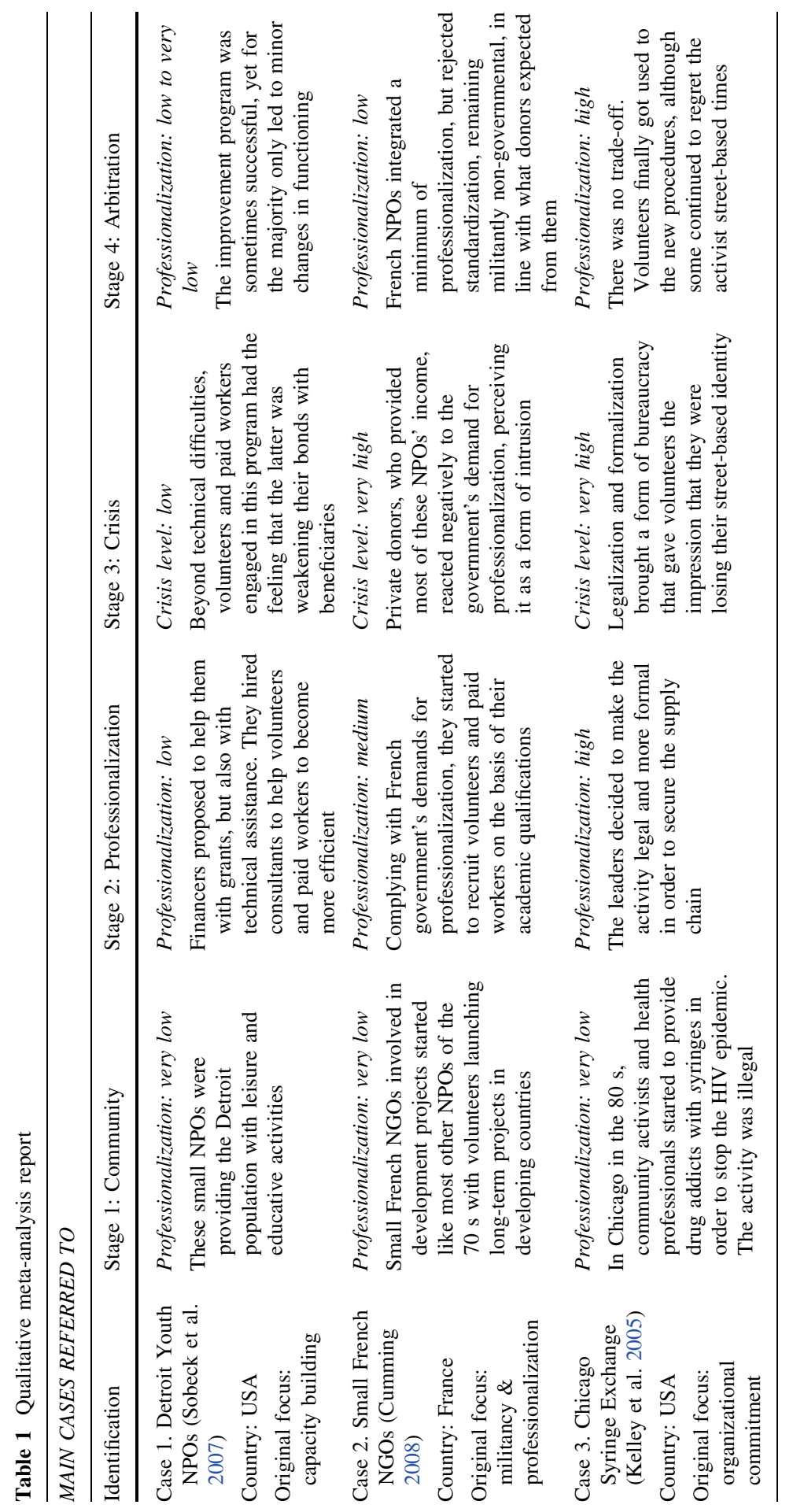




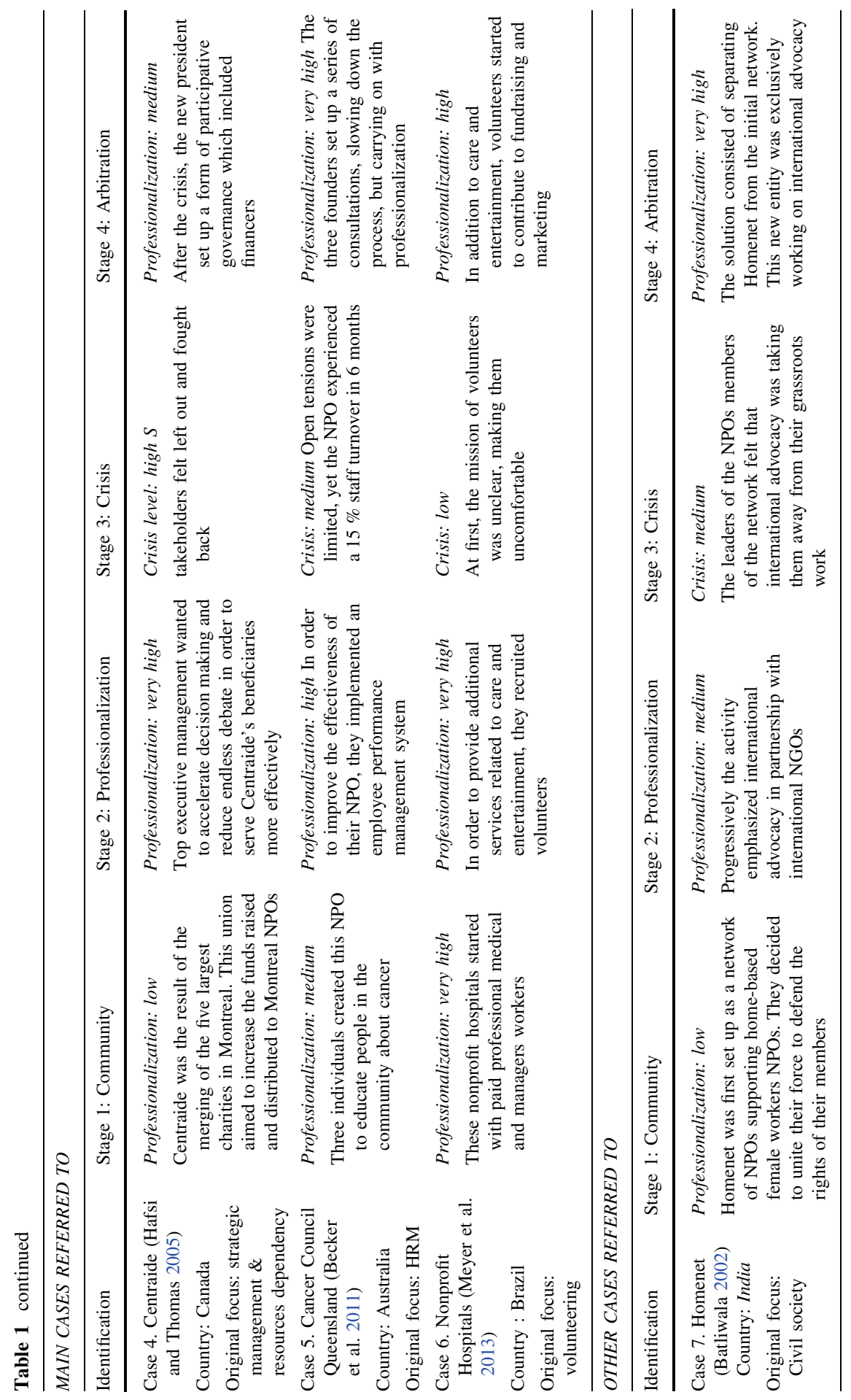




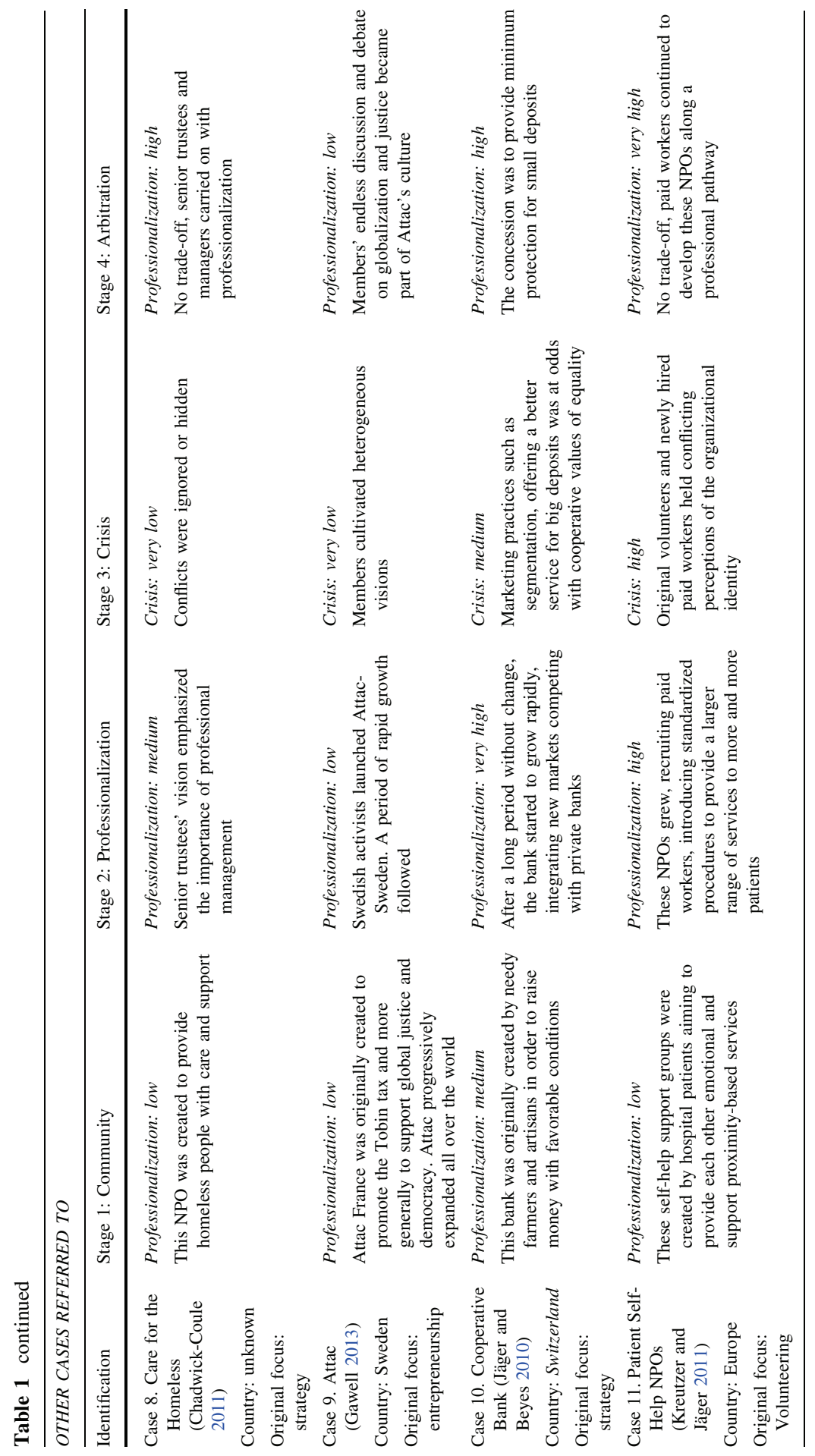




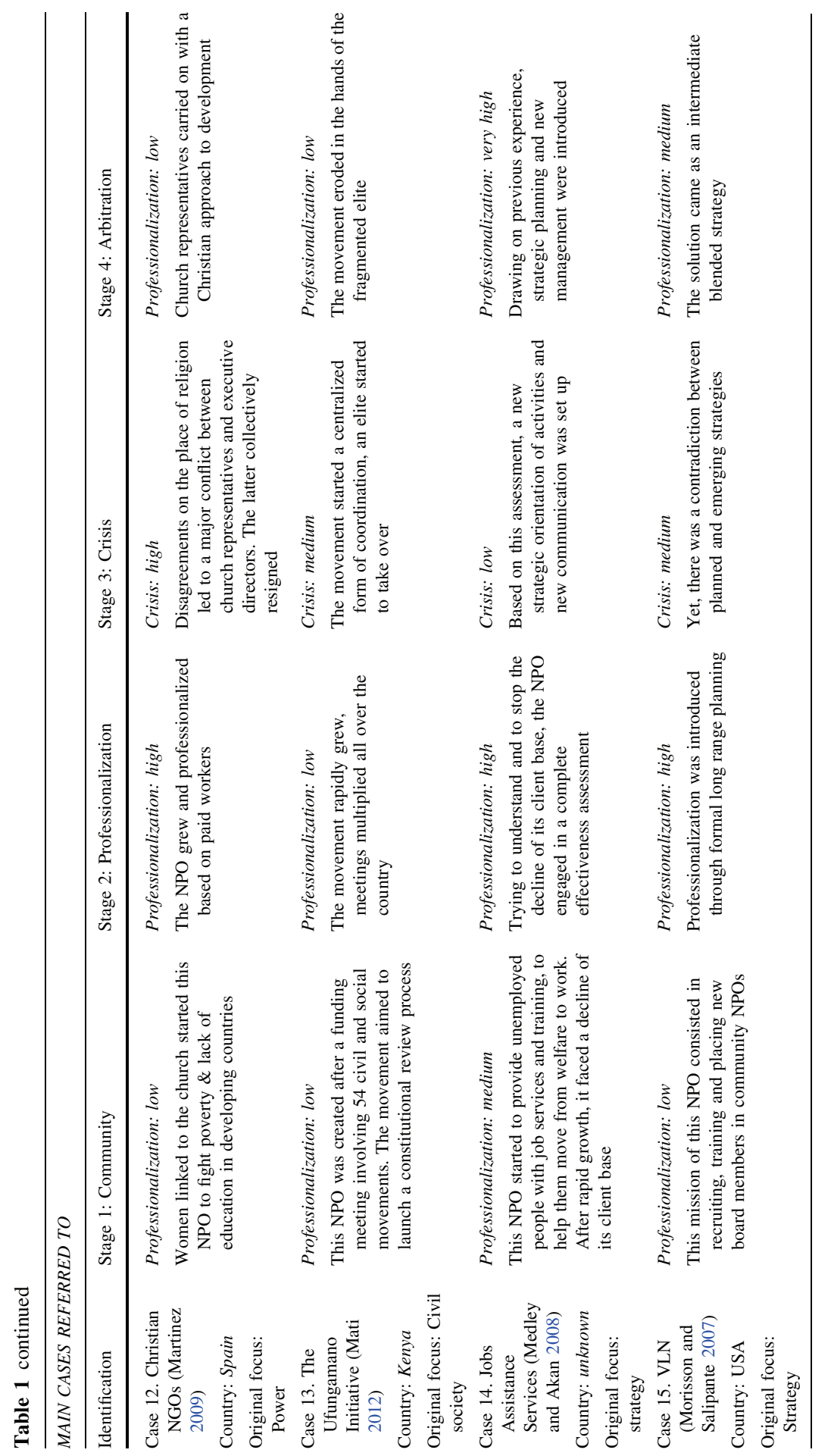




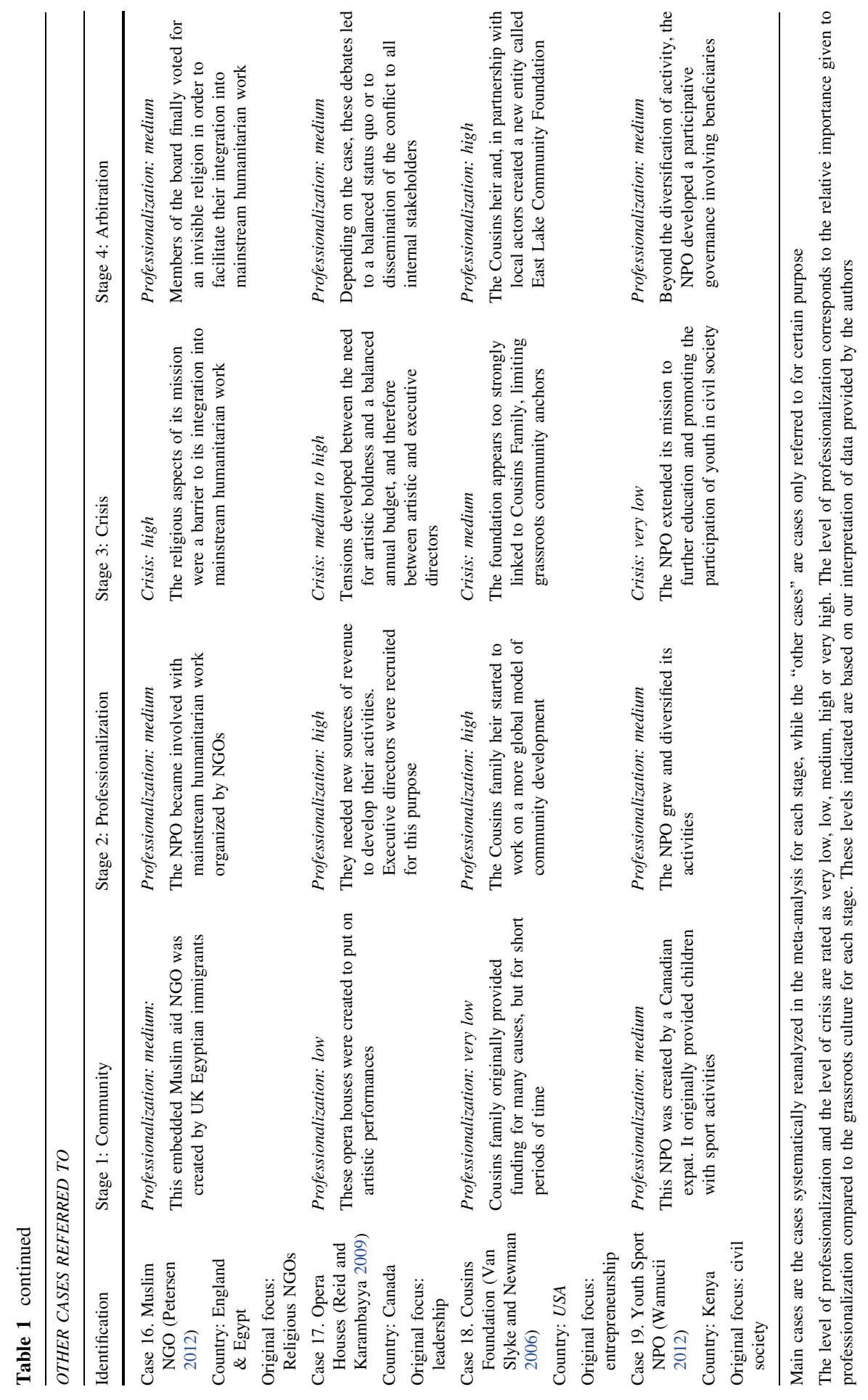




\section{References}

Anheier, H. K. (2005). Nonprofit organizations. New York: Rootledge.

Barnard, C. (1938). The functions of the executive. Cambridge, MA: Harvard Press.

Batliwala, S. (2002). Grassroots movements as transnational actors. Voluntas: International Journal of Voluntary and Nonprofit Organizations, 13, 393-409.

Battilana, J., Leca, B., \& Boxenbaum, E. (2009). Agency and institutions. Academy of Management Annals, 3, 65-107.

Baum, J. A. C., \& Amburgey, T. L. (2002). Organizational Ecology. In J. A. C. Baum (Ed.), Companion to Organizations (pp. 304-326). Oxford: Blackwell.

Becker, K., Antuar, N., \& Everett, C. (2011). Implementing an employee management performance system in a NPO. NML, 21(3), 255-271.

Bird, B. J., Gartner, W. B., \& Starr, J. A. (1992). Acting as if. Entrepreneurship: Theory and Practice, $16(3), 13-31$.

Brandsen, T. (2009). Civicness in organizations. Voluntas: International Journal of Voluntary and Nonprofit Organizations, 20, 260-273.

Bui, L.T., and Alam, L. (2008). Multi-Objective optimization in computation intelligence. www.igiglobal.com.

Carman, J. G. (2010). The accountability movement. NVSQ, 39(2), 256-274.

Chadwick-Coule, T. (2011). Social dynamics and the strategy process. NVSQ, 40, 33-56.

Chew, C., \& Osborne, S. P. (2005). Identifying the factors that influence positioning strategy in the UK. NVSQ, 38, 28-50.

Coch, L., \& French, J. R. P. (1948). Overcoming resistance to change. Human Relations, 1(4), 512-532.

Cumming, G. D. (2008). French NGOs in the global era. Voluntas, 19, 372-394.

De Prins, P., \& Hendericks, E. (2007). HRM effectiveness. NVSQ, 36, 549-571.

Dees, J. J. (1998). The meaning of social entrepreneurship. Kansas: Kauffman Foundation.

DiMaggio, P. J., \& Powell, W. W. (1983). The iron cage revisited: Institutional isomorphism and collective rationality in organzational fields. American Sociological Review, 48, 147-160.

DiMaggio, P. J., \& Powell, W. W. (1991). The New Institutionalism in Organizational Analysis. Friedland: University of Chicago Press.

Durkheim, E. (1893-1984). The division of labor in society. New York: The Free Press.

Ebrahim, A., \& Rangan, V. K. (2010). The limits of nonprofit impacts. Harvard Business School, 10-099.

Finkelstein, S., \& Boyd, B. K. (1998). How much does the CEO matter? Academy of Management Journal, 41, 179-199.

Freeman, R. E. (2010). Stakeholder theory. Cambridge: Cambridge University Press.

Gawell, M. (2013). Social entrepreneurship. Voluntas: International Journal of Voluntary and Nonprofit Organizations, 24, 1071-1090.

Graddy, E., \& Wang, L. (2009). Community foundation development and social capital. NVSQ, 38, $392-412$.

Greiner, L. A. (1998). Evolution and revolution as organizations grow. Harvard Business Review, May, 55-67 (modified reprint from July-August 1972).

Hafsi, T., \& Thomas, H. (2005). Strategic management and change in high dependency environment. Voluntas, 16, 329-351.

Hoon, C. (2013). Meta-Synthesis of Qualitative Case Studies. Organizational Research Methods, 16(4), 522-556.

Hrebeniak, L. G., \& Joyce, W. F. (1985). Organizational adaptation. Administrative Science Quarterly, 30, 336-349.

Hwang, H., \& Powell, W. W. (2009). The rationalization of charity. Administrative Science Quarterly, 54, 268-298.

Jäger, U., \& Beyes, T. (2010). Strategizing in NPOS. Voluntas: International Journal of Voluntary and Nonprofit Organizations, 21, 82-100.

Jun, K. N., \& Shiau, E. (2012). How are we doing? NVSQ, 41(4), 632-655.

Kanter, R. M., \& Summers, D. (1987). Doing well while doing good. In W. W. Powell (Ed.), The nonprofit sector: A research handbook (pp. 154-166). New Haven, CT: Yale University Press.

Kelley, M., Lune, H., \& Murphy, S. (2005). Doing syringe exchange. NVSQ, 34, 362-386.

Kreutzer, K., \& Jäger, U. (2011). Volunteering versus managerialism. NVSQ, 40(4), 634-661.

Lewin, K. (1952). Field Theory in Social Science. New-York: Harper and Raw. 
Martinez, B. R. (2009). Structures, power and discourses of development. NML, 20(2), 203-218.

Mati J. M. (2012). Social movements \& socio-political change in Africa. Voluntas. 23:63-84.

McDonald, R. E. (2007). An investigation of innovation in nonprofit organization. NVSQ, 36(2), 256-281.

Medley, B. C., \& Akan, O. H. (2008). Creating positive change in community organizations. NML., 18(4), 485-496.

Meyer, V., Pascucci, L., \& Murphy, P. J. (2013). Volunteers in Brazilian hospitals. Voluntas, 24, 293-310.

Miles, M., \& Huberman, A. M. (1994). Qualitative Data Analysis. Thousand Oaks, CA: Sage Publications.

Mintzberg, H. (1983). Power in and around organizations. Englewood Cliffs, N.J.: Prentice-Hall.

Mintzberg, H., \& Waters, J. A. (1985). Of Strategies, Deliberate and Emergent. Strategic Management Journal, 6(3), 257-272.

Moore, M. H. (2000). Managing for value. NVSQ, 29, 183-204.

Morrison, J. B., \& Salipante, P. (2007). Governance for broadened accountability. NVSQ, 36(2), 195-217.

Muukkonen, M. (2009). Civil society and related concepts. NVSQ, 38, 684-700.

Ospina, S., Diaz, W., \& O’Sullivan, J. F. (2002). Negotiating accountability. NVSQ, 30, 5-31.

Pache, A. C., \& Santos, F. M. (2010). When worlds collide. Academy of Management Review, 35(3), $455-476$.

Petersen, M. J. (2012). Islamizing aid. Voluntas: International Journal of Voluntary and Nonprofit Organizations, 23, 126-155.

Pfeffer, J., \& Salancik, G. R. (1978). The external control of organization. New York, NY: Harper \& Row.

Reid, W., \& Karambayya, R. (2009). Impact of dual executive leadership dynamics in creative organizations. Human Relations, 7, 1073-1112.

Ridder, H. G., \& McCandless, A. (2010). Influences of the architecture of HRM in NPO. NVSQ, 39(1), $124-141$.

Rothschild, J., \& Stephenson, M. J. (2009). The meaning of democracy in non-profit and community organizations. American Behavioral Scientist, 52, 800-806.

Schmid, H. (2006). Leadership styles and leadership change. NML, 17(2), 179-194.

Siciliano, J. I. (2008). A comparison of CEO and director perceptions of board involvement in strategy. NVSQ, 37, 152-162.

Simon, H. A. (1984). Models of Bounded Rationality. Boston, MA: MIT Press.

Simon, J. S. (2009). The five life stages of nonprofit organizations. Saint-Paul, MN: Wilder.

Sloan, M. F. (2009). The effects of nonprofit accountability ratings on donor behaviour. NVSQ, 38, 220-236.

Sobeck, J., Agius, E., \& Mayers, V. N. (2007). Supporting and sustaining grassroots youth organizations. Voluntas, 18, 17-33.

Sowa, J. E., Selden, S. C., \& Sandfort, J. R. (2004). No longer unmeasurable? Nonprofit and Voluntary Sector Quarterly, 33(4), 711-728.

Stevens, S. K. (2001). Nonprofit lifecycles. Wayzata, M.N: Stagewise Enterprise Inc.

Sulek, M. (2010). On the modern meaning of philanthropy. NVSQ, 35(3), 385-408.

Tucker, D. J., \& Summerfeld, D. H. (2006). The larger they get. NVSQ, 35, 183-203.

Van Slyke, D. M., \& Newman, H. K. (2006). Venture philanthropy and social entrepreneurship in community redevelopment. $N M L, 16(3), 345-368$.

Verbruggen, S., Christiaens, J., \& Milis, K. B. (2011). Can resource dependence and coercive isomorphism explain NPOs' compliance with reporting standards? NVSQ, 40(1), 5-32.

Wamucii, P. (2012). Youth agency, sport and the public sphere in senya. Voluntas, 23, 26-42.

Watzlavick, P., Weakland, J. H., \& Fisch, R. (1974). Change, principles of problems formation and problem resolution. New York: Norton.

Weick, K. (1995). Sensemaking in organizations. London: Sage.

Whetten, D. A. (1989). What constitutes a theoretical contribution? Academy of Management Review, 14(4), 490-495.

Withman, J. R. (2008). Evaluating foundations according to their social values. $N M L, 18(4), 417-434$. 